\title{
Risk-Adapted Chemotherapy in the Adjuvant Setting of Breast Cancer
}

Adjuvant chemotherapy leads to significant improvements in overall and disease-free survival in breast cancer patients. However, there are two major problems in the field of adjuvant chemotherapy:

(1) The threshold of risk at which adjuvant cytotoxic chemotherapy is deemed necessary has become very low. The preliminary results of a large randomized US trial (NSABP B-20) showed that 5-year survival rates of women with good-prognosis early breast cancer (estrogen-receptor-positive/node-negative) was improved by $3 \%$ (from 94 to $97 \%$ ) by the use of adjuvant cytotoxic chemotherapy in comparison to tamoxifen alone [1]. However, in contrast to node-positive patients, $60-70 \%$ of node-negative patients are cured by locoregional surgery and radiotherapy alone. Until now the recommendations for adjuvant chemotherapy in node-negative cancer depend on age, tumor size, grading and hormone receptor expression. It would be of advantage if high-risk, node-negative patients could be selected for adjuvant chemotherapy by different prognostic factors.

Factors capable of quantifying the invasive and metastatic capacity of malignant cells should be suitable for estimation of prognosis. Evidence has accumulated that invasion and metastasis in solid tumors require the action of tumor-associated proteases, which promote the dissolution of the tumor matrix and the basement membranes. The urokinase-type plasminogen activator UPA and its inhibitor PAI-1 are strong and independent prognostic markers in breast cancer [2]. Since UPA and PAI-1 are independent prognostic factors, high- or low-risk patients can be identified even within the classical risk groups defined by lymph node status, hormone receptor status or menopausal status. This might be of importance for clinical decision-making in node-negative breast cancer in the future.

(2) According to the 1998 St. Gallen Consensus Conference, CMF (cyclophosphamide, methotrexate, fluorouracil) or AC (doxorubicin, cyclophosphamide) is still the standard of care for node-negative and all node-positive breast cancer patients. However, we have accumulating data that at least CMF is no longer the gold standard in the adjuvant treatment of high-risk breast cancer patients with $\geq 4$ positive nodes, and these patients will receive inadequate treatment.
Already in 1995, Bonadonna et al. [3] published the 20-year survival rates of CMF vs. control in the adjuvant therapy of node-positive breast cancer patients. Subgroup analysis demonstrated that only patients with $1-3$ positive nodes had a significant benefit from adjuvant CMF (38\% survival rate) vs. control (24\% survival rate). There was no advantage in survival rate from CMF in patients with $4-9$ of $\geq 10$ positive nodes. In 1998, Levine et al. [4] published the results of a phase III trial in node-positive premenopausal women. The patients were randomized between a classical CMF regimen and CEF (cyclophosphamide, epirubicin, fluorouracil). Dose intensity of epirubicin was $30 \mathrm{mg} / \mathrm{m}^{2} /$ week. The results of this trial showed the superiority of CEF over CMF in terms of both disease-free and overall survival. Subgroup analysis again demonstrated that especially patients with $\geq 4$ positive nodes had a significant benefit in relapse-free survival. The metaanalysis of the EBCTCG in 1998 [5] also showed a benefit for anthracyclinecontaining regimes in comparison to non-anthracycline-containing regimens.

The benefit of the concept of increasing the dose intensity is still unproven. Recent data from NSABP B-22 and B-25, testing doses of cyclophosphamide from $600 \mathrm{mg} / \mathrm{m}^{2}$ every 21 days $\times 4$ up to $2,400 \mathrm{mg} / \mathrm{m}^{2}$ did not suggest an advantage [6]. However, escalated dose levels of epirubicin might improve disease-free and overall survival of patients with node-positive breast cancer. Increasing the epirubicin dose from 50 to $100 \mathrm{mg} / \mathrm{m}^{2}$ resulted in an $11.5 \%$ difference in disease-free survival and a $10 \%$ difference in overall survival after a followup of 5 years [7]. This observation was confirmed also by other groups. Beside the controversies of CMF vs. anthracyclinecontaining regimens and of the impact of dose intensity, the question of sequential vs. combination chemotherapy is also of major importance. From both a theoretical [8] and a clinical point of view $[9,10]$ sequential chemotherapy may be superior to combination chemotherapy. In a Milan study [9], women with 4 or more positive nodes were randomly assigned to treatment consisting of alternating $\mathrm{CMF}$ and doxorubicin (represented as CCACCA...) or sequential (i.e., more dose-dense) therapy, with all 4 cycles of doxorubicin preceding all 8 cycles of CMF (represented as AAAACCCCCCCC). Ten-year survival rates were higher for sequential therapy (58 vs. $44 \%$ ).

\begin{tabular}{ll}
\hline KARGER & ( 2000 S. Karger GmbH, Freiburg \\
Fax +49 761 4520714 & Accessible online at: \\
$\begin{array}{l}\text { E-mail Information@Karger.de } \\
\text { www.karger.com }\end{array}$ & www.karger.com/journals/onk
\end{tabular}


Another area of chemotherapy research concerns the role of newer agents, specifically the taxanes. The first large randomized trial testing the addition of paclitaxel to standard AC to be reported (CALGB 9344) demonstrated a significant improvement in disease-free and overall survival for the sequential regimen [10]. This trial recruited patients with positive nodes. Subgroup analysis is awaited with great interest. A similar trial from the NSABP (B-28) should serve to confirm or clarify the results reported by the CALGB.

Sequential dose-dense chemotherapy may further improve long-term results in high-risk patients. Hudis et al. [11] reported the results of a dose-dense sequential doxorubicin $\left(90 \mathrm{mg} / \mathrm{m}^{2}\right)$, paclitaxel $\left(250 \mathrm{mg} / \mathrm{m}^{2}\right)$ and cyclophosphamide $\left(3.0 \mathrm{~g} / \mathrm{m}^{2}\right) \mathrm{reg}-$ imen ('ATC'). Only high-risk patients with 4 or more positive nodes were treated. Patients received 3 cycles of each drug, using 14-day inter-treatment intervals. All cycles were given with subcutaneous injections of $5 \mu \mathrm{g} / \mathrm{kg}$ G-CSF on days 3 through 10. 42 patients were enrolled, the median number of positive nodes was 8 . At a median follow-up from surgery of 48 months, the actuarial disease-free survival rate was $78 \%$.

A German AGO trial tested a modification of this regimen. Doxorubicin was substituted by epirubicin ('ETC'), and the infusion time of paclitaxel was reduced from 24 to $3 \mathrm{~h}$. This phase I/II dose escalation study clearly showed that especially hematological toxicity was significantly reduced [12]. Phase III studies are currently running to evaluate these regimens in the adjuvant setting. An American Intergroup study is comparing the ATC regimen against high-dose consolidation, and a
German AGO-Intergroup trial is comparing the ETC regimen against a modification of the CALGB 9344 regimen [ 4 cycles of EC $\left(90 / 600 \mathrm{mg} / \mathrm{m}^{2}\right)$ followed by 4 cycles of paclitaxel $\left.\left(175 \mathrm{mg} / \mathrm{m}^{2}\right)\right]$. Both trials are recruiting quickly and will help to answer the important question as to which chemotherapeutic regimen will be most effective in the high-risk group of patients with $\geq 4$ positive nodes.

High-dose trials with peripheral stem cell support predominantly recruited patients with $\geq 10$ positive nodes. According to the ASCO meeting last year, the question remains open as to whether high-dose chemotherapy shows any benefit in comparison to conventional-dosed chemotherapy or dose-intensified CEF. To answer this question, a longer follow-up of the reported trials is required and the pending results of ongoing trials are needed.

Summarizing, there is a lot of evidence that the CMF regimen is not appropriate for high-risk patients with more than 4 positive nodes. These patients should receive at least an anthracycline-containing regimen with an epirubicin dose intensity of $30 \mathrm{mg} / \mathrm{m}^{2} /$ week. If sequential $\mathrm{EC} \rightarrow \mathrm{T}$ (epirubicin, cyclophosphamide, paclitaxel) proves to be superior in all subgroups (1-3, 4-9, $\geq 10$ lymph nodes), a new standard will be defined. Although the question of dose escalation in the adjuvant setting is still unproven, new schedules like dose-dense sequential therapy (ETC) or high-dose regimens are under investigation and may be superior to conventional-dosed regimens in high-risk patients with $\geq 4$ or $\geq 10$ positive nodes.

V. Möbus, Ulm

\section{References}

1 Fisher B, Dignam J, Decellis A, Wickerham DL, et al: The worth of chemotherapy and tamoxifen (TAM) over TAM alone in node-negative patients with estrogen-receptor (ER) positive invasive breast cancer (BC): First results from NSABP B-20. Proc ASCO 1997;16:1(abstract).

2 Duffy MJ, Reilly D, McDermott E, O'Higgins N, Fennelly JJ, Andreasen PA: Urokinase plasminogen activator as a prognostic marker in different subgroups of patients with breast cancer. Cancer 1994; 74:2276-2280.

3 Bonadonna G, Valagussa P, Moliterni A, Zambetti M, Brambilla C: Adjuvant cyclophosphamide, methotrexate, and fluorouracil in node-positive breas cancer. N Engl J Med 1995;332:901-906.

4 Levine MN, Bramwell VH, Pritchard KI, Shepherd LE, Abu-Zahra H, Findlay B, Warr D, Bowman D, Myles J, Arnold A, Vandenberg T, MacKenzie R, Robert J, Ottaway J, Burnell M, Williams CK, Tu D for the National Cancer Institute of Canada, Clinica Trials Group: Randomized trial of intensive cyclophosphamide, epirubicin, and fluorouracil chemotherapy compared with cyclophosphamide, methotrexate, and fluorouracil in premenopausal women with node-positive breast cancer. J Clin Oncol 1998; 16:2651-2658.
5 Early Breast Cancer Trialists' Collaborative Group Polychemotherapy for early breast cancer: An overview of the randomised trials. Lancet 1998;352 930-942.

6 Fisher B, Anderson S, Wickerham DL, DeCillis A, Dimitrov N, Mamounas E, Wolmar KN, Pugh R, Atkins JN, Meyers FJ, Abramson N, Wolter J, Bornstein RS, Levy L, Romond EH, Caggiano V, Grimald M, Jochimsen P, Deckers P: Increased intensification and total dose of cyclophosphamide in a doxorubicincyclophosphamide regimen for the treatment of primary breast cancer. Findings from National Surgical Adjuvant Breast and Bowel Project B-22. J Clin Oncol 1997;15:1858-1869.

7 Bonneterre J, Roché H, Bremond A, Kerbrat P, Namer M, Fumoleau P, Goudier M-J, Fargeot P, Bardonnet M, Marcillac I, Luporsi E on behalf of the French Adjuvant Study Group (FAS6): Results of a randomized trial of adjuvant chemotherapy with FEC 50 vs FEC 100 in high-risk node-positive breast cancer patients. Proc ASCO 1998;17:473(abstract).

8 Norton L, Simon R: The Norton-Simon hypothesis revisited. Cancer Treat Rep 1986;70:163-169.
9 Bonadonna G, Zambetti M, Valagussa P: Sequential or alternating doxorubicin and CMF regimens in breast cancer with more than three positive nodes. Ten-year results. JAMA 1995;273:542-547.

10 Henderson IC, Berry D, Demetri G, Cirrincione C, Goldstein L, Martino S, Ingle JN, Cooper MR, Canellas G, Borden E, Fleming G, Holland JF, Graziano S, Carpenter J, Muss H, Norton L, for CALGB, ECOG, SWOG and NCCTG: Improved disease-free (DFS) and overall survival (OS) from the addition of sequential paclitaxel $(\mathrm{T})$ but not from the escalation of doxorubicin (A) dose level in the adjuvant chemotherapy of patients (pts) with node-positive primary breast cancer (BC). Proc ASCO 1998; 17:390A(abstract).

11 Hudis C, Seidman A, Baselga J, Raptis G, Lebwohl D, Gilewski D, Moynahan M, Sklarin N, Fennelly D, Crown JPA, Surbone A, Uhlenhopp M, Riedel E, Yaso TJ, Norton L: Sequential dose-dense doxorubicin, paclitaxel, and cyclophosphamide for resectable high-risk breast cancer: Feasibility and efficacy. J Clin Oncol 1999;17:93-100.

12 Möbus V, Lück H-J, Untch M, Nitz U, Kuhn W, Pfaff P, Kreienberg R: Sequential dose-dense epirubicin (E), paclitaxel (T) and cyclophosphamide (C) in breast cancer patients with 4-9 positive nodes: A phase I/II study. J Cancer Res Clin Oncol 1998;124(suppl):R65. 